\title{
PERSEPSI MASYARAKAT HUTAN MANGROVE BAHOWO DI KELURAHAN TONGKAINA KECAMATAN BUNAKEN KOTA MANADO
}

\author{
Enggelina Baraoh \\ Jenny Baroleh \\ Welson Marthen Wangke
}

\begin{tabular}{ll}
\hline Naskah diterima melalui Website Jurnal Ilmiah agrisosioekonomi@ unsrat.ac.id & $:$ Senin, 12 Juli 2019 \\
Disetujui diterbitkan & $:$ Kamis, 25 Juli 2019 \\
\hline
\end{tabular}

\begin{abstract}
The purpose of the study was to determine the public perception of the Bahowo mangrove forest. This research was conducted in Bahowo, Tongkaina Sub-District, Bunaken District, Manado City. The study lasted for 3 (three) months from August to November 2018 starting from preparation to writing the final report. The selection of respondents was done purposevely.This study used primary data and secondary data. Primary data was obtained through direct interviews with 20 respondents based on a list of prepared statements. Secondary data was obtained through documentation from agencies related to this study, among others, at the Tongkaina District Office in Bunaken District, Manado City, local bookstore and the internet using a google search engine to access scientific journal articles and thesis from others universities regarding people's perceptions of mangrove forests. This research showed that the community has positve perceptions of mangrove forests. Bahowo in Tongkaina Sub-District, Bunaken Sub-District, Manado City as a whole stated that he agreed with a total score of 1,714 judgments from the statements conveyed by the community through direct interviews and by calculating the overall score to determine the community's perception of mangrove forests. The community argued that mangrove forests play a very important role for local communities such as protecting from the dangers of high waves and tsunami hazards. ${ }^{*}$ eprm*
\end{abstract}

Keywords: community perception, mangrove forest, Bahowo, Manado City

\begin{abstract}
ABSTRAK
Tujuan penelitian yaitu untuk mengetahui persepsi masyarakat terhadap hutan mangrove Bahowo. Penelitian ini dilaksanakan di Bahowo Kelurahan Tongkaina Kecamatan Bunaken Kota Manado. Penelitian berlangsung selama 3 (tiga) bulan dari bulan Agustus sampai November 2018 mulai dari persiapan sampai dengan penulisan laporan akhir. Penelitian ini menggunakan data primer dan data sekunder. Pemilihan responden dilakukan secara sengaja. Data primer diperoleh melalui wawancara langsung dengan 20 responden berdasarkan daftar pernyataan yang telah disiapkan. Data sekunder diperoleh melalui dokumentasi dari instansi-instansi yang berkaitan dengan penelitian ini antara lain di Kantor Kelurahan Tongkaina Kecamatan Bunaken Kota Manado, buku-buku yang tersedia di toko buku lokal dan internet menggunakan mesin pencari google untuk mengakses artikel jurnal ilmiah dan skripsi dari perguruan tinggi lain yang menyangkut persepsi masyarakat terhadap hutan mangrove. Hasil penilaian dari responden untuk persepsi masyarakat terhadap hutan mangrove. Bahowo di Kelurahan Tongkaina Kecamatan Bunaken Kota Manado secara keseluruhan menyatakan setuju dengan skor total bobot 1.714 penilaian dari pernyataan-pernyataan yang sudah di sampaikan oleh masyarakat melalui wawancara langsung dan dengan cara perhitungan skor secara keseluruhan untuk mengetahui persepsi masyarakat terhadap hutan mangrove. Masyarakat memiliki persepsi positif karena mereka berpendapat bahwa hutan mangrove berperan sangat penting bagi masyarakat setempat seperti melindungi dari bahaya gelombang tinggi dan bahaya tsunami. ${ }^{*}$ erm* $^{*}$
\end{abstract}

Kata kunci: persepsi masyarakat, hutan mangrove, Bahowo, Kota Manado

Agrisosioekonomi:

Jurnal Transdisiplin Pertanian (Budidaya Tanaman, Perkebunan, Kehutanan, Peternakan, Perikanan), Sosial dan Ekonomi 


\section{PENDAHULUAN}

\section{Latar Belakang}

Indonesia dikenal sebagai negara kepulauan dengan perairan terluas. Hingga kini negara kita memiliki 17.508 pulau dengan garis pantai sepanjang $81.000 \mathrm{~km}$. Dengan garis pantai sepanjang itu, maka dapat digambarkan bahwa penduduk Indonesia yang bermukim di daerah pesisir saat ini diperkirakan mencapai 140 juta jiwa atau sekitar 60 persen penduduk Indonesia tinggal dan bermukim di daerah pesisir.

Provinsi Sulawesi Utara memiliki hutan mangrove seluas 11,456 hektar tersebar di 13 kota dan kabupaten dengan kondisi yang berbeda. Di Bahowo Kelurahan Tongkaina merupakan salah satu hutan mangrove yang tersisa di pinggiran kotaManado dan menjadi sorotan pemerintah. Sampai saat ini 70 persen mangroveBahowo masih bertahan dan 30 persennya akan mendapatkan proses penyulaman, yakni pohon mangrove yang sudah mati akan dihidupkan kembali dan sekarang pemerintah Kota Manado akan menjadikan Bahowo sebagai kampung wisata sehingga pemerintah menyediakan fasilitas untuk menunjang pambangunan kampung wisata.

Pengertian masyarakat menurut Maclver dan Page dalam Soekanto (2009) masyarakat adalah suatu sistem dari kebiasaan dan tata cara, dari wewenang dan kerja sama antara berbagai kelompok dan penggolongan dan pengawasan tingkah laku serta kebebasan-kebebasan manusia

Mangrove di Kelurahan Tongkaina lingkungan IVBahowo Kecamatan Bunaken Kota Manado menjadi hal yang sangat penting bagi warga di kelurahan tersebut. Berbeda dengan beberapa tahun sebelumnya, tanaman ini justru menjadi obyek eksploitasi warga dengan menebang dan menghancurkan lahan tanaman mangrove.

Kepentigan ekonomi dari eksploitasi tanaman mangroveuntuk dijadikan kayu bakar (kayu api) untuk dijual, masih diutamakan ketimbang merawat dan mempertahankan tanaman tersebut.Kegiatan eksploitasi mangrove ini seakan menjadi lumrah dan legal pada saat itu, padahal fungsi mangrove sebagai wadah yang menjaga bioekologis, pelindung garis pantai dari terpaan gelombang yang berdampak pada abrasi, serta tempat untuk berkembangbiaknya biota laut, maupun biota darat seperti reptil, dan aves (burung) masih belum dipahami oleh masyarakat apalagi terkait pengaruhnya terhadap kegiatan ecotourism.

\section{Rumusan Masalah}

Berdasarkan latar belakang yang telah dikemukakan maka yang menjadi masalah yaitu bagaimana persepsi masyarakat terhadap hutan mangrove Bahowo di Kelurahan Tongkaina Kecamatan Bunaken Kota Manado?

\section{Tujuan Penelitian}

Tujuan penelitian yaitu untuk mengetahui persepsi masyarakat terhadap hutan mangrove Bahowo di Kelurahan Tongkaina Kecamatan Bunaken Kota Manado.

\section{Manfaat Penelitian}

Manfaaat penelitian yaitu:

a. Bagi masyarakat sebagai informasi dan pengetahuan untuk menambah wawasan tentang hutan mangrove.

b. Bagi pemerintah, sebagai bahan kajian dalam mengambil keputusan dan masukan untuk mengembangkan desa wisata hutan mangrove.

c. Bagi peneliti, menambah wawasan dan pengetahuan untuk pentingnya manfaat hutan mangrove bagi masyarakat yang tinggal di pesisir pantai.

\section{METODE PENELITIAN}

\section{Tempat dan Waktu Penelitian}

Penelitian ini telah dilaksanakan diBahowo Kelurahan Tongkaina Kecamatan Bunaken Kota Manado. Penelitian berlangsung selama 3 (tiga) bulan dari bulan Agustus sampai November 2018 mulai dari persiapan sampai dengan penulisan laporan akhir.

\section{Metode Pengambilan Sampel}

Teknik pengambilan sampel adalah Purposive Sampling (ditentukan secara sengaja) yaitu teknik pengambilan sampel yang digunakan dalam situasi dimana seorang peneliti menggunakan penilaiannya dalam memilih responden dengan tujuan tertentu didalam benaknya (Ibrahim, 2015). Jumlah responden yang diambil sebanyak 20 orang diBahowo Lingkungan IV Kelurahan Tongkaina Kecamatan Bunaken Kota Manado.

\section{Metode Pengumpulan Data}

Penelitian ini menggunakan data primer dan data sekunder. Data primer diperoleh melalui wawancara langsung dengan responden berdasarkan daftar pernyataan yang telah disiapkan (Kuesioner), sedangkan data sekunder diperoleh melalui dokumentasi dari instansi-instansi yang berkaitan dengan penelitian ini antara lain di Kantor Kelurahan Tongkaina Kecamatan Bunaken Kota manado. 


\section{Konsep Pengukuran Variabel}

Variabel-variabel yang diukur dalam penelitian ini, adalah:

1. Identitas Responden

a. Nama Responden

b. Umur, dinyatakan dengan satuan tahun

c. Jenis Kelamin (laki-laki/perempuan)

d. d.Tingkat pendidikan, diukur menurut tingkatan pendidikan yang sudah ditamatkan yaitu SD, SMP, SMA, Perguruan Tinggi

e. Pekerjaan yaitu pekerjaan yang dijalani oleh responden

2. Persepsi Masyarakat terhadap Mangrove

Persepsi masyarakat terhadap Mangrove diukur dengan pernyataan menyangkut:

a. Reklamasi pantai terhadap hutan mangrove.

b. Hutan mangrove dijadikan tempat wisata oleh pemerintah kota

c. Manfaat hutan mangrove bagi masyarakat.

\section{Analisis Data}

Tahap analisis data bertujuan untuk mengetahui persepsi masyarakat terhadap MangroveBahowo di Kelurahan Tongkaina Kecamatan Bunaken Kota Manado Analisis data yang digunakan dalam penelitian ini adalah analisis data deskriptif dengan menggunakan pengukuran pengskalaan Likert dengan menggunakan tabel data dan angka. Jumlah pertanyaan untuk mengukur persepsi masyarakat sebanyak 20 item pertanyaan dengan jumlah responden 20 orang yang di ambil secara acak.

Analisis data yang digunakan merupakan analisis deskriptif yang dianalisis dengan menggunakan Skala Likert (Likert Scale) dimana menurut Riduwan (2008) sebagai berikut:

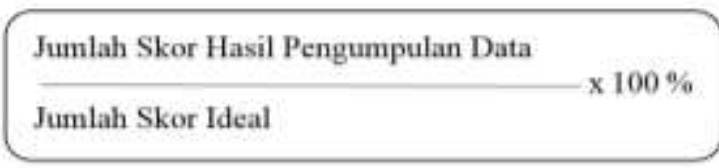

\begin{tabular}{|c|c|c|}
\hline \multicolumn{3}{|c|}{ Keterangan interpretas skor: } \\
\hline ST: Setuju & shor: 5 & Angka Oo.40\% = Tidak sctuju \\
\hline RR-Ragu-Ragu & skor: 3 & Angka $41 \%-60 \%=$ Ragu-nagu \\
\hline T5: Tidak setuji & skar: 2 & Angka $61 \% 100 \%=$ Setuja \\
\hline
\end{tabular}

Dengan cara perhitumpan skor

Junlahskor Tiap Kriteria = Capaian SkorX Jumbih Responden $55=5 \times 20=100$ $54-3 \times 20-60$ $53-2 \times 20-40$

\section{HASIL DAN PEMBAHASAN}

Gambaran Umum Daerah Penelitian Gambaran umum tentang Kelurahan Tongkaina meliputi sejarah, letak geografi dan batas-batas wilayah, kondisi pendudukmenurut jenis kelamin, tingkat pendidikan, mata pencaharian, dan agama dijelaskan sebagai berikut:

Sebelah Utara : Desa Tiwoho

Sebelah Selatan : Kelurahan Meras

Sebelah Timur : Hutan Lindung

Sebelah Barat : Tepi Laut

\section{Kelurahan Tongkaina}

Nama Tongkaina berasal dari bahasa Tonsea yang berarti Potong Tanjung pada tahun 1970, Dotu Sualang memanggil keluarganya untuk berkebun di tanah tersebut.Selanjutnya banyak orang yang bermukim atau tinggal di tempat tersebut.Dotu Sualang akirnya menjadi Tuaimbalakyang artinya kepala pejuang pada tahun 1884 meninggal dunia, pada waktu itu pula masyarakat Tongkaina mengadakan musyawarah untuk menunjuk pengganti yaitu Doto Enggres yang akhirnya menjadi Tipalayang artinya kepala kampong.

Pada tahun 1885 datang serangan pencurian dari orang yang berasal dari Mangindano yang bermaksud mencuri makanan berupa padi dan lainlain.Pada waktu itu Doto Enggres memerintahkan seluruh masyarakat tanpa terkecuali untuk menjaga di dalam kampung dan di tiap-tiap rumah menyediakan bambu runcing bersama fonslok atau dodorobe yang berisikan air rica (cabe).

Pada tahun 1887 Doto Enggres meninggal dunia dan atas keputusan dari kepala distrik Lodwik Wakarry yang menggantikan Dotu Enggres adalah adik dari Lodwik Wakarry yang bernama Alexander Wakarry dan pada tahun 1903 warga desa Tongkaina sebagian sudah berkebun di tempat bernama Tiwow yang artinya dalam bahasa Tonsea yaitu kano-kano.

Pada tahun 1904 dikeluarkan peraturan kebun-kebun harus diukur dan harus terdaftar dalam register kampung Tongkaina dan yang memiliki tanah atau kebun tersebut harus membayar kepada pemerintah setempat akan tetapi pada saat itu masyarakat belum tahu bagaimana mengukur tanah-tanah mereka. Sehingga seluruh tua-tua kampung menyewa kadasterBelanda untuk mengukur kebun-kebun rakyat tersebut. Kebun-kebun yang sudah diukur tersebut dinamakan negri. 
Pada tahun 1924 hukum tua Tongkaina Eduard Rumengan diundang ke kampung Wori dengan maksud melakukan musyawarah untuk pengukuran tanah desa Tiwow dan kampung Wori yang akan dimasukkan dalam register dan dua kampung tersebut disahkan pada tahun 1930 di Wori.

Pada tahun 1930 hukum tua mengumpulkan masyarakat Tongkaina untuk mensahkan perombakan-perombakan tanah atau kebun yang sudah diukur dan di masukkan dalam register yang kedua selanjutnya disahkan pada tahun 1932 seluruh orang-orang tua dan pemerintah melakukan musyawarah untuk membuat lapangan sepakbola. Keputusan negeri harus membayar kepada keluarga Rumengan dengan bukti tempat tersebut bernama plein yang terletak di sebelah timur dibawa kampung Tongkaina.

Pada tahun 1943 Desa Tongkaina dan Wori sudah diduduki oleh pemerintahan Jepang yang disebut kapetai. Pada tahun tersebut atas perintah dari tentara Jepang, tiap-tiap kepala rumahtangga harus membuat kebun serta menanam pohon kapas, apabila tidak ada yang mengindahkan perintah tersebut maka akan di hukum dengan cara potongbore.Pada tanggal 7 Mei 1959 seluruh rakyat Tongkaina mengungsi di Tumumpa karena kampung tersebut dibakar oleh permesta yang di pimpin oleh Anis Tangka. Pengungsian masyarakat Tongkaina sebagian ke wilayah Manado dan sebagian kecil mengungsi di pulau-pulau yang ada di sekitar Manado.

Seiring dengan perjalanan waktu dan peralihan pemerintahan akhirnya Tongkaina yang dulunya berstatus desa akhirnya menjadi kelurahan berdasarkan Perda No 4 Tahun 2000 tentang status desa menjadi kelurahan.

\section{Penduduk Menurut Jenis Kelamin Di Kelurahan Tongkaina}

Penduduk Kelurahan Tongkaina menurut jenis kelamin, menunjukkan bahwa penduduk laki-laki lebih banyak jumlahnya dari penduduk perempuan yaitu berjumlah 943 orang laki-laki $(50,54 \%)$ dibandingkan dengan penduduk perempuan 923 orang $(49,46 \%)$.

\section{Penduduk menurut Tingkat Pendidikan Di Kelurahan Tongkaina}

Latar belakang pendidikan akan mempengaruhi dalam kehidupan maupun pekerjaan.Tabel 1 menunjukkan tingkat pendidikan responden mulai dari Taman Kanak-Kanak sampai Perguruan Tinggi.Penduduk yang paling banyak adalah Tamat Sekolah Dasar (SD) berjumlah 590 orang dengan persentase $31,61 \%$ sedangkan penduduk yang tingkat pendidikan D1 sampai D3 sangat rendah berjumlah 8 orang dengan persentase $0,42 \%$.
Tabel 1 . Penduduk menurut Tingkat Pendidikan di Kelurahan

\begin{tabular}{|c|c|c|c|}
\hline No & Tingkat Pendidikan & Jumlah & Persentase (\%) \\
\hline 1. & Tidak pernah sekolah & 350 & 18,75 \\
\hline 2. & Belum Sekolah & 181 & 9,69 \\
\hline 3. & Sedang TK & 50 & 2,67 \\
\hline 4. & Tamat Sekolah Dasar & 590 & 31,61 \\
\hline 5. & Tamat SLTP & 307 & 16,45 \\
\hline 6. & Tamat SLTA & 368 & 19,72 \\
\hline 7. & Tamat D1 & 4 & 0,21 \\
\hline 8. & Tamat D3 & 4 & 0,21 \\
\hline \multirow[t]{2}{*}{9.} & Tamat Sarjana (S1) & 12 & 0,64 \\
\hline & Jumlah & 1866 & 100 \\
\hline
\end{tabular}

Sumber : Kantor Kelurahan Tongkaina, Tahun 2019

\section{Penduduk menurut Mata Pencaharian Di Kelurahan Tongkaina}

Penduduk menurut mata pencaharian menjelaskan mengenai jenis-jenis mata pencaharian yang tersedia di Kelurahan Tongkaina.Jenis-jenis mata pencaharian ini yang merupakan sumber pendapatan penduduk.Penduduk Kelurahan Tongkaina menurut mata pencaharian dapat dilihat pada Tabel 2.Tabel 2 menunjukkan bahwa penduduk yang terbanyak adalah yang tidak bekerja dengan jumlah 475 orang dengan persentase 25,24\% sedangkan jumlah penduduk yang bekerja sebagai tukang cuci, tukang ojek, Polri,TNI, peternak dengan jumlah 8 orang dengan persentase $0,4 \%$.

Tabel 2. Penduduk menurut Mata Pencaharian

\begin{tabular}{llll}
\hline No & Mata Pencaharian & Jumlah & Persentase (\%) \\
\hline 1. & Tidak bekerja & 471 & 25,24 \\
2. & Pelajar & 376 & 20,15 \\
3. & Ibu rumahtangga (IRT) & 356 & 19,07 \\
4. & Karyawan swasta & 206 & 11,03 \\
5. & Buruh & 167 & 8,94 \\
6. & Petani & 129 & 6,91 \\
7. & Karyawan perusahaan & 44 & 2,35 \\
8. & Nelayan & 39 & 2,09 \\
9. & Pedagang kelontong & 26 & 1,39 \\
10. & Wiraswasta & 15 & 0,80 \\
11. & PNS & 12 & 0,64 \\
12. & Sopir & 9 & 0,48 \\
13. & Guru & 5 & 0,26 \\
14. & Bidan & 3 & 0,16 \\
15. & TNI/Polri & 3 & 0,16 \\
16. & Tukang cuci & 2 & 0,10 \\
17. & Ojek & 2 & 0,10 \\
18. & Peternak & 1 & 0,05 \\
\hline & Jumlah & 1866 & 100 \\
\hline Sula
\end{tabular}

Sumber : Kantor Kelurahan Tongkaina, Tahun 2015.

\section{Penduduk Menurut Agama di Kelurahan Tongkaina}

Penduduk menurut agama yang ada di Kelurahan Tongkaina dapat dilihat pada Tabel 3yang menunjukkan kebanyakan penduduk memeluk agama kristen berjumlah 1416 orang dengan persentase $75,88 \%$ sedangkan yang paling sedikit memeluk agama islam berjumlah 450 orang dengan persentase $24,11 \%$.

Tabel 3. Penduduk Menurut Agama di Kelurahan Tongkaina

\begin{tabular}{lllc}
\hline No & Agama & Jumlah & Persentase (\%) \\
\hline 1. & Kristen & 1416 & 75,88 \\
2. & Islam & 450 & 24,12 \\
\hline & Jumlah & 1866 & 100 \\
\hline
\end{tabular}

Sumber : Kantor Kelurahan Tongkaina, Tahun 2015. 


\section{Karakteristik Responden}

\section{Umur}

Klasifikasi umur responden di Keluraan Tongkaina ditunjukkan pada Tabel 4 bahwa persentase umur yang tertinggi dari responden berada pada umur muda yaitu dibawa usia 30 tahun dengan jumlah 6 orang $(30 \%)$ dan umur tergolong tua sebanyak 3 responden (15\%) dengan umur berada antara 61 sampai 70 tahun.

Tabel 4. Klasifikasi Responden Menurut Kelompok Umur

\begin{tabular}{|c|c|c|c|c|}
\hline No & $\begin{array}{l}\text { Kelompok } \\
\text { Responden }\end{array}$ & Umur & Jumlah & Persentase $(\%)$ \\
\hline 1 & $<30$ tahun & & 6 & 30 \\
\hline 2 & 30 - 40 tahun & & 5 & 25 \\
\hline 3 & $41-50$ tahun & & 4 & 20 \\
\hline 4 & $51-60$ tahun & & 2 & 10 \\
\hline \multirow[t]{2}{*}{5} & $61-70$ tahun & & 3 & 15 \\
\hline & Jumlah & & 20 & 100 \\
\hline
\end{tabular}

Sumber :Data Primer, Tahun 2019.

\section{Jenis Kelamin Responden}

Klasifikasi responden berdasarkan jenis kelamin dapat di lihat pada Tabel 5. Tabel ini menunjukkan bahwa jumlah responden berdasarkan jenis kelamin sebagian besar adalah perempuan berjumlah 13 orang dengan persentase $65,00 \%$ sedangkan laki-laki berjumlah 7 orang dengan persentase $35,00 \%$.

Tabel 5. Klasifikasi Responden Menurut Jenis Kelamin

\begin{tabular}{llll}
\hline No & Jenis Kelamin & Jumlah & Persentase (\%) \\
\hline 1 & Perempuan & 13 & 65 \\
2 & Laki-laki & 7 & 35 \\
\hline & Jumlah & 20 & 100 \\
\hline
\end{tabular}

Sumber :Data Primer, Tahun 2019.

Dari 20 informan ini masing-masing terdiri dari 4 orang dari unsur pemerintah, 4 orang dari tokoh masyarakat, 4 orang tokoh agama, 4 orang dari LSM, dan 4 orang dari unsur masyarakat.

\section{Pendidikan Responden}

Klasifikasi responden berdasarkan tingkat pendidikan ditunjukkan pada Tabel 6 . Pada Tabel 6 dapat dilihat bahwa sebagian besar responden memiliki tingkat pendidikan tamat SD dengan jumlah 10 orang dengan persentase $50,00 \%$ dan tingkat pendidikan SMA/SMK berjumlah 7orang dengan persentase $35,00 \%$ dan tamat SMP berjumlah 2 orang dengan persentase $10,00 \%$ dan S1 berjumlah 1 orang dengan persentase $5,00 \%$.
Tabel 6. Responden menurut Tingkat Pendidikan

\begin{tabular}{llll}
\hline No & Tingkat Pendidikan & Jumlah & Persentase (\%) \\
\hline 1 & Sekolah Dasar (SD) & 10 & 50 \\
2 & SLTP & 2 & 10 \\
3 & SLTA/SMK & 7 & 35 \\
4 & Sarjana (S1) & 1 & 5 \\
\hline & Jumlah & 20 & 100
\end{tabular}

Sumber :Data Primer, Tahun 2019

\section{Pekerjaan Responden}

Untuk mengetahui klasifikasi responden berdasarkan jenis pekerjaan dapat di lihat pada Tabel 7 .

\begin{tabular}{|c|c|c|c|}
\hline No & Pekerjaan Responden & Jumlah & Persentase $(\%)$ \\
\hline 1 & Ibu Rumah Tangga & 12 & 60 \\
\hline 2 & Karyawan Swasta & 3 & 15 \\
\hline 3 & Nelayan & 2 & 10 \\
\hline 4 & Petani & 1 & 5 \\
\hline 5 & Guru & 1 & 5 \\
\hline \multirow[t]{2}{*}{6} & Tour Guide & 1 & 5 \\
\hline & Jumlah & 20 & 100 \\
\hline
\end{tabular}

Sumber :Data Primer, Tahun 2019

Tabel 7 menunjukkan bahwa jumlah terbanyak responden merupakan ibu rumahtangga (IRT) yaitu sebanyak 12 orang dengan persentase $60,00 \%$, karyawan swasta berjumlah 3 orang $(15,00 \%)$, nelayan berjumlah 2 orang $(10,00 \%)$ petani berjumlah 1 orang dan guru berjumlah 1 orang dan tour guide berjumlah 1 orang dengan prentasi $0,5 \%$.

\section{Persepsi Masyarakat Terhadap Hutan Mangrove}

Persepsi masyarakat terhadap hutan mangrove dalam penelitian ini menyangkut penilaian positif maupun negatif yang diberikan oleh anggota masyarakat terhadap hutan mangrovee. Hutan mangrove yang ada Bahowo di Kelurahan Tongkaina ini merupakan salah satu benteng alam yang tersisa ditengah gempuran reklamasi pantai. Untuk mengetahui bagaimana tanggapan anggota masyarakat tentang adanya hutan mangrove ini dibuat pernyataan dan setiap responden menanggapinya sesuai dengan persepsi mereka. 


\section{Rangkuman Persepsi Masyarakat Terhadap Hutan Mangrove Bahowo Di Kelurahan Tongkaina Kecamatan Bunaken Kota Manado}

Tabel 28 menunjukkan bahwa hasil penilaian dari 20 orang responden untuk persepsi masyarakat terhadap hutan mangrove Bahowo di Kelurahan Tongkaina Kecamatan Bunaken Kota Manado secara keseluruhan menyatakan setuju dengan skor total bobot 1.714 penilaian dari pernyataan-pernyataan yang sudah di sampaikan oleh masyarakat melalui wawancara langsung dan dengan cara perhitungan skor secara keseluruhan untuk mengetahui persepsi masyarakat terhadap hutan mangrove.

Tabel 28. Rekapitulasi Persepsi Masyarakat Terhadap Hutan Mangrove Bahowodi Kelurahan Tongkaina Kecamatan Bunaken Kota Manado

\begin{tabular}{|c|c|c|c|c|c|}
\hline No & Variabel & Sub Variabel & Nilai & Keterangan & Alasan \\
\hline 1 & $\begin{array}{l}\text { Reklamasi } \\
\text { Pantai } \\
\text { Terhadap } \\
\text { Hutan } \\
\text { Mangrove }\end{array}$ & $\begin{array}{l}\text { 1. Persepsi Masyarakat Terhadap Hutan } \\
\text { Mangrove Untuk Reklamasi Pantai } \\
\text { 2. Persepsi Masyarakat Terhadap } \\
\text { Peraturan Pemerintah Tidak Boleh } \\
\text { Menebang Pohon Mangrove Sembarangan } \\
\text { 3. Persepsi Masyarakat Terhadap Hutan } \\
\text { Mangrove Di Tebang Dan Di Jadikan } \\
\text { Bangunan Resort }\end{array}$ & $\begin{array}{l}97 \\
44\end{array}$ & $\begin{array}{l}\text { Tidak } \\
\text { setuju } \\
\text { Setuju } \\
\text { Tidak } \\
\text { setuju }\end{array}$ & $\begin{array}{l}\text { Masyarakat tidak setuju karena tidak } \\
\text { terima kalau hutan mangrove yang } \\
\text { sudah di rawat dan dijaga } \\
\text { kelestarianya akan di rusak oleh dan } \\
\text { di bagun infrastruktur }\end{array}$ \\
\hline 2 & $\begin{array}{l}\text { Hutan } \\
\text { Magrove } \\
\text { Dijadikan } \\
\text { Tempat } \\
\text { Wisata } \\
\text { Oleh } \\
\text { Pemerintah } \\
\text { Kota }\end{array}$ & $\begin{array}{l}\text { 4. Persepsi Masyarakat Terhadap Hutan } \\
\text { Mangrove Dijadikan Desa Wisata } \\
\text { 5. Persepsi Masyarakat Terhadap Hutan } \\
\text { Mangrove Di Jadikan Agrowisata } \\
\text { 6. Persepsi Masyarakat Terhadap } \\
\text { Keikutsertaan Pemerintah Dalam } \\
\text { Pemeliharaan Hutan Mangrove } \\
\text { 7. Persepsi Masyarakat Terhadap Hutan } \\
\text { Mangrove Yang Sudah Rusak Di Tanam } \\
\text { Kembali } \\
\text { 8. Persepsi Masyarakat Terhadap LSM } \\
\text { Membantu Masyarakat Dalam } \\
\text { Pemeliharaan Mangrove }\end{array}$ & $\begin{array}{l}92 \\
95 \\
100 \\
100 \\
100\end{array}$ & $\begin{array}{l}\text { Setuju } \\
\text { Setuju } \\
\text { Setuju } \\
\text { Setuju } \\
\text { Setuju }\end{array}$ & $\begin{array}{l}\text { Masyarakat Setuju Pemrintah Kota } \\
\text { Menjadikan Tempat wisata agar bisa } \\
\text { menambah pemasukan ekonomi bagi } \\
\text { pemerintah setempat dan ,masyarakat } \\
\text { setempat dan Bahowo Makin } \\
\text { terkenal Sampai luar negeri Dan } \\
\text { pemerintah juga menunjang untuk } \\
\text { membuat tempat wisata tersebut }\end{array}$ \\
\hline 3 & $\begin{array}{l}\text { Manfaat } \\
\text { Hutan } \\
\text { mangrove } \\
\text { Bagi } \\
\text { Masyarakat }\end{array}$ & $\begin{array}{l}\text { 9. Persepsi Masyarakat Terhadap } \\
\text { Manfaat Mangrove Bagi } \\
\text { Masyarakat } \\
\text { 10. Persepsi Masyarakat Terhadap } \\
\text { Manfaat Mangrove Bagi Kesehatan } \\
\text { 11. Persepsi Masyarakat Terhadap Hutan } \\
\text { Mangrove Sebagai Pemecah Ombak } \\
\text { 12. Persepsi Masyarakat Terhadap } \\
\text { Sampah Pada Hutan Mangrove } \\
\text { 13. Persepsi Masyarakat Terhadap } \\
\text { Mangrove Di Jadikan Kayu Bakar } \\
\text { 14. Persepsi Masyarakat Terhadap Hutan } \\
\text { Mangrove Berfungsi Sebagai } \\
\text { Budidaya Ikan, Udang, Kepiting } \\
\text { 15. Persepsi Masyarakat Terhadap } \\
\text { Mangrove Yang Sudah Kering Di Jadikan } \\
\text { Kayu Bakar } \\
\text { 16. Persepsi Masyarakat Terhadap Hutan } \\
\text { Mangrove Menguntungkan } \\
\text { Masyarakat Bagi } \\
\text { 17. Persepsi Masyarakat Terhadap Hutan } \\
\text { Mangrove Sebagai Tempat Berkembang } \\
\text { Biak Biota Laut } \\
\text { 18. Persepsi Masyarakat Terhadap Hama } \\
\text { Paling Berbahaya Dalam Hutan Mangrove } \\
\text { Adalah Manusia } \\
\text { 19. Persepsi Masyarakat Terhadap Hutan } \\
\text { Mangrove Sangat Penting Bagi } \\
\text { Masyarakat } \\
\text { 20. Persepsi Masyarakat Terhadap Peduli } \\
\text { Kebersihan Hutan Mangrove } \\
\text { Mana }\end{array}$ & $\begin{array}{l}100 \\
98 \\
100 \\
67 \\
41 \\
88\end{array}$ & $\begin{array}{l}\text { Setuju } \\
\text { Setuju } \\
\text { Setuju } \\
\text { Tidak } \\
\text { Setuju } \\
\text { Tidak } \\
\text { Setuju } \\
\text { Setuju } \\
\text { Setuju } \\
\text { Setuju } \\
\text { Setuju }\end{array}$ & $\begin{array}{l}\text { Masyarakat sangant merasakan } \\
\text { manfaat hutang mangrove karena } \\
\text { masyarakat boleh terlindung dari } \\
\text { bahaya gelombang tinggi dan } \\
\text { tsunami dan juga memeberi oksigen } \\
\text { bagi manusia }\end{array}$ \\
\hline
\end{tabular}

Sumber: dirangkum dari tabel-tabel yang diolah dari Data Primer, tahun 2019 
Jumlah skor seluruh kriteria $=$

$\mathrm{S} 5=5 \times 20=100 \times 20=2000 \quad$ capaian jumlah skor

$\mathrm{S} 3=3 \times 20=60 \times 20=1.200 \times$ jumlah responden

$\mathrm{S} 2=2 \times 20=40 \times 20=800 \quad \times$ jumlah pernyataan

Jumlah skor ideal untuk keseluruhan pernyataan 2000 (setuju) sedangkan jumlah skor terendah yaitu 800(tidak setuju). Berdasarkan hasil pengolahan data, maka diperoleh total skor 1.714. Hal ini dapat digambarkan untuk persepsi secara keseluruhan sebagai berikut:

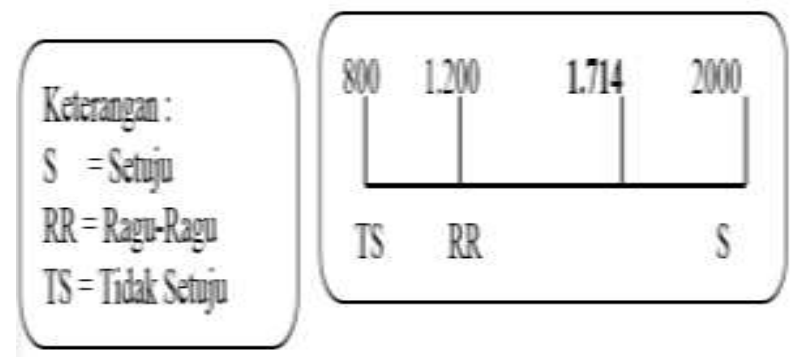

Jumlah skor terbanyak 1.714 untuk persepsi masyarakat secara keseluruhan skor (1200 sampai 2000) yang dikategorikan setuju, menyatakan bahwa masyarakat di Kelurahan Tongkaina Kecamatan Bunaken Kota Manado, setuju dengan adanya hutan mangrove ini karena masyarakat berpendapat bahwa hutan mangrove berperan sangat penting bagi masyarakat setempat seperti melindungi dari bahaya gelombang tinggi dan bahaya tsunami.

Riduwan (2008) menyatakan dalam rumus sebagai berikut:

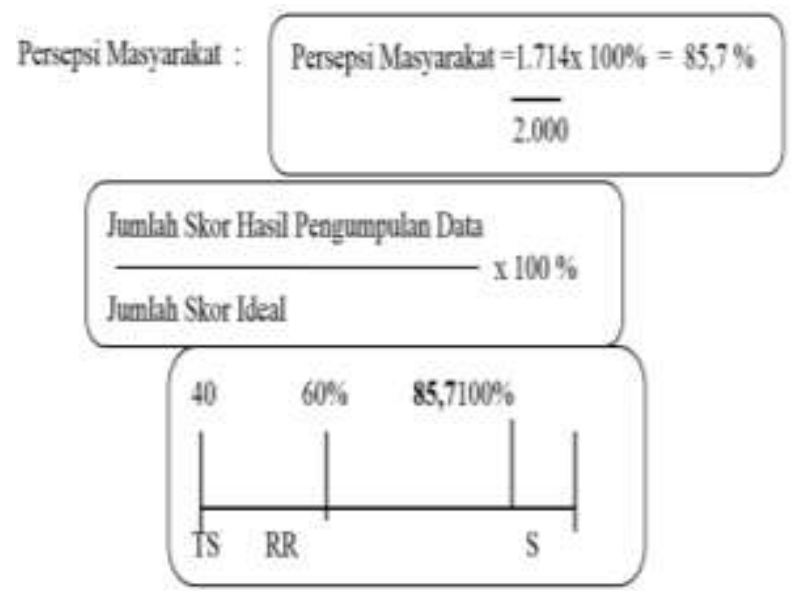

Skala persepsi masyarakat terhadap hutan mangrove secara keseluruhan persentase berdasarkan hasil analisis menggunakan skala likert dapat diketahui bahwa angka indeks persepsi masyarakat terhadap hutan mangrove di Kelurahan Tongkaina Kecamatan Bunaken Kota Manado yaitu sebesar $85,7 \%$ dan tergolong dalam kategori setuju.Hal ini menunjukkan bahwa persepsi masyarakat terhadap hutan mangrove sangat baik dimana masyarakat setuju dengan adanya hutan mangroveini.Masyarakat merasa sangat terlindungi dari bahaya ombak tinggi, dan ketika bahaya tsunami datang dan juga ada sebagian pohon dari hutan mangrove dapat dijadikan obat-obatan untukbeberapa penyakit salah satunya penyakit diaredan demam. Kawasan hutan mangrove ini sudah dijadikan kawasan agrowisata dan sudah menghasilkan pendapatan untuk pemerintah setempat.

\section{KESIMPULAN DAN SARAN}

\section{Kesimpulan}

Persepsi masyarakat terhadap hutan mangroveBahowo di Kelurahan Tongkaina Kecamatan Bunaken Kota Manado sangat baik karena masyarakat setuju dengan program dari pemerintah. Masyarakat merasa terlindungi dengan adanya hutan mangrovesebagai benteng alam dan membawa dampak yang sangat baik bagi masayarakat dan pemerintah setempat serta menambah pendapatan masyarakat dan pemerintah setempat.

\section{Saran}

Hutan mangrove dapat dikembangkan lagi dan dijaga kelestariannya dan dilindungi agar tidak ada lagi penebangan liar dan pembangunan yang merusak ekosistem hutan ini. Pemerintah kota tetap memberikan bantuan untuk pengelolaan dan pelestarian hutan mangrove serta pengawasan khusus terhadap pertumbuhan mangrove ini. 


\section{DAFTAR PUSTAKA}

Dimas, Wihayanto dan Asbar Laga.2010. Kajian

Pengelolaan Hutan Mangrove di Kawasan

Konservasi di Desa Mamburungan Kota

Tarakan Kalimantan Timur.

Saintek.Vol.2.No.1.

Lestari alamku Oxigen For Manado; Senin 25 september 2017; Save The Earth; Catatan:Jelly'ching'siwy. 